\title{
STUDIES OF RENAL OXYGEN CONSUMPTION IN MAN. I. THE EFFECT OF TUBULAR LOADING (PAH), WATER DIURESIS AND OSMOTIC (MANNITOL) DIURESIS ${ }^{1}$
}

\author{
By JOHN KAPP CLARK 2 AND HAROLD G. BARKER ?
}

(From the University of Pennsylvania School of Medicine and Hospital, Philadelphia, Pa.)4

(Submitted for publication January 16, 1951; accepted April 23, 1951)

\section{INTRODUCTION}

The energy demands of increased functional activity of the body as a whole are met by increased oxygen consumption with a high degree of thermodynamic efficiency amounting to 25 or 30 per cent (1). In the case of cardiac or skeletal muscle or secreting glands this relationship seems straightforward, but it is less obvious with brain or kidney. In the case of kidney, thermodynamic calculations by other workers $(2,3)$ indicate that the theoretical oxygen equivalent of the work necessary to produce maximal osmolar gradients between plasma and bladder urine is small relative to the resting metabolism of the organ. Experimental testing of this relationship by direct measurements in animals has resulted in contradictory reports (4-8). Since failure of experimental unanimity may have been due, in part, to differences in species, preparation or anesthesia, and since changes in renal oxygen consumption may be related to many factors other than mere overall osmotic gradients, it seemed advisable to make these measurements in unanesthetized man. Aside from their theoretical interest, such data might help in understanding the concepts of "renal work" and "resting the kidney" on the clinical level where they are stressed in all discussions of therapy but do not have an unequivocal background on the basis of either theory or experiment.

\footnotetext{
${ }^{1}$ Presented to the American Physiological Society, Detroit, Mich., April 21, 1949.

2 This work was done during the tenure of a National Institutes of Health Post Doctorate Fellowship.

${ }^{3}$ Harrison Fellow in Surgical Research.

1 This work was supported by the Department of Medicine, The Harrison Department of Surgical Research and C. Mahlon Kline Fund for developments in the Department of Medicine.
}

\section{General}

Measurements of glomerular filtration rate, renal blood flow and renal oxygen consumption were made before and during test procedures in 15 adult male subjects between the ages of 17 and 58 years of age none of whom had evidence of renal disease. Clearances were performed in general according to the techniques described by Goldring and Chasis (9), and values were corrected to 1.73 square meters surface area. Constant infusions of test solutions, mannitol and para-aminohippurate (PAH), were given intravenously by means of a motor driven worm screw pushing on the barrel of a $50 \mathrm{cc}$. syringe according to the technique of Earle and Berliner (10). PAH and mannitol were mixed in the same solution; this procedure, however, causes no reduction in PAH extraction and clearance such as has been described with mixtures of PAH and glucose where presumably a coupling reaction occurs in which the p-amino group of the PAH is covered (11). Urine was collected by catheter with bladder washings. Blood samples were taken simultaneously from the femoral artery by means of an indwelling needle and from the right renal vein by means of a catheter. Before sampling, $5 \mathrm{cc}$. of blood were withdrawn from the artery and $10 \mathrm{cc}$. from the renal vein to clear the systems. These quantities were demonstrated to be adequate by testing in vitro with dye solutions. After sampling, this blood was reinjected. Blood to be analysed for excretory substances (mannitol, PAH and creatinine) was taken into dry syringes and transferred to tubes containing powdered heparin. Blood for gas analysis was taken anaerobically into $10 \mathrm{cc}$. syringes wet with liquid heparin. One cc. of mercury was introduced, the syringes were capped and kept in ice until analysed. This interval was sometimes as long as six hours in cases where a great many specimens were taken, but if the blood is adequately iced no measurable deterioration of oxygen content occurs in this time. Since analysis of each arterial sample was immediately followed by analysis of its paired venous sample, any undetected deterioration would tend to be minimized in the arterio-venous difference.

\section{Test procedures}

After control observations varying from about 30 to 60 minutes' duration and consisting of two or three urine collection periods and one or two arterio-venous oxygen differences, one of the following experimental procedures, designed to change renal work, was instituted. 
$P A H$ saturation: In five subjects the rate of excretion of PAH by the tubules was increased from values of 11-16 $\mathrm{mg} . / \mathrm{min}$. to maximal rates of $71-86 \mathrm{mg} . / \mathrm{min}$. by increasing the rate of $\mathrm{PAH}$ infusion after an additional priming dose, thus raising the $\mathrm{PAH}$ plasma concentration from low levels of around $2 \mathrm{mg} . / 100 \mathrm{cc}$. to higher levels of around $30 \mathrm{mg} . / 100 \mathrm{cc}$.

Water diuresis: In five subjects tap water was given by mouth in varying amounts, depending on the subject's capacity, and measurements made after water diuresis had been established.

Osmotic diuresis: In five subjects mannitol was injected intravenously as a priming dose of 12.5 to 50 grams followed by a constant infusion of 194 to $262 \mathrm{mg} . / \mathrm{min}$.

\section{Calculation of renal functions}

Renal blood flow (RBF) was determined by application of the Fick principle using $\mathrm{PAH}$ as a test substance, according to the equation $\mathrm{RBF}=\frac{\mathrm{UV}}{\mathrm{A}-\mathrm{R}} \times \frac{1}{1-\mathrm{Hct}}$, where $\mathrm{V}$ equals the rate of urine formation in cc./min.; $U, A$ and $R$ equal the concentration of $\mathrm{PAH}$ in $\mathrm{mg} . / \mathrm{cc}$. in urine, arterial plasma and renal venous plasma respectively; and Hct. is the arterial hematocrit. Determined values for A-R from simultaneously drawn samples were plotted against time on semilogarithmic paper and the interpolated value at the mid-point of each urine collection period was used to calculate RBF. Glomerular filtration rate (GFR) was measured as endogenous creatinine clearance (Ccr) in all cases and as mannitol clearance $(\mathrm{Cm})$ in some. Total renal oxygen consumption $\left(\mathrm{TQ}_{\mathrm{O}_{2}}\right)$ was calculated as the product of RBF and renal arterio-venous oxygen difference $(A-R)_{0_{2}}$. Data have been expressed as cc./100 grams/min. $\left(Q_{\mathrm{O}_{2}}\right)$ on the assumption that 300 grams of renal tissue are equivalent to 1.73 square meters surface area, i.e., $Q_{0_{2}}=\mathrm{TQ}_{0_{2}} / 3$. In each case, control values of $\mathrm{RBF}$ and $(\mathrm{A}-\mathrm{R})_{0_{2}}$ were averaged and these averages multiplied together to calculate $\mathrm{TQ}_{0_{2}}$. Experimental values were treated in the same manner. To avoid the possibility of error in (A-R $)_{0_{2}}$ estimations, arising from changes in hemoglobin concentration in passage through the kidney or by unequal dilution in the sampling syringes by liquid heparin or traces of saline remaining in the venous catheter, values for renal venous oxygen content have been corrected to the same hemoglobin content as the simultaneously drawn specimen from the femoral artery according to the following formula. $\mathbf{R}_{\mathbf{O}_{2 \mathrm{C}}}=\mathbf{R}_{\mathbf{O}_{2} \mathrm{D}}$ $\times \mathrm{AHb} / \mathrm{RHb}$, when $\mathrm{R}_{\mathbf{0}_{2} \mathrm{C}}$ is the corrected, and $\mathrm{R}_{\mathbf{0}_{2 \mathrm{D}}}$ the determined value for oxygen content of renal venous blood in vols. per cent, and $\mathrm{AHb} / \mathrm{RHb}$ is the ratio of hemoglobin concentration in the femoral artery to that in the renal vein. This value, $A H b / R H b$, averaged 0.997 in 47 determinations with a standard deviation of 0.027 and a standard error of the mean of 0.004 . The range, however, was from 0.913 to 1.050 , and while these corrections are small compared to the total oxygen content of either arterial or renal venous blood, they may constitute a sizeable fraction of the relatively small (A-R) $)_{2}$. In 11 instances the correction was zero but in 10 it was greater than 0.50 vol. per cent. The mean of the differences
$\mathbf{R}_{\mathbf{0}_{2} \mathrm{C}}-\mathbf{R}_{\mathbf{0}_{2} \mathrm{D}}$ was not statistically significantly different from zero but this merely indicates that $\mathrm{AHb}$ tended to exceed $\mathrm{RHb}$ as frequently as $\mathrm{RHb}$ exceeded $\mathrm{AHb}$. These changes are probably not due to errors in the hemoglobin method, since we have found in 42 sets of triplicate determinations (assuming 1 gram of hemoglobin to be equivalent to 1.34 cc. of oxygen) that the maximum change in (A-R) ${ }_{0}$ resulting from error in $\mathrm{AHb} / \mathrm{RHb}$ should have been less than 0.2 vol. per cent in 95 per cent of the cases. On the basis of subsequent work, we are inclined to believe that one factor in this difference was unequal dilution of the arterial and renal venous blood by the liquid heparin in the sampling syringes. Similar results of about the same magnitude have been reported by other workers in the $\operatorname{dog}(1,12,13)$ although smaller differences have been found in $\operatorname{man}(14,15)$.

\section{Chemical determinations}

Blood oxygen content was determined in duplicate on 1 cc. samples by the manometric method of Van Slyke and Neill for simultaneous determinations of carbon dioxide and oxygen (16). In all determinations gas was thus liberated by means of a combined reagent containing lactic acid. Under these conditions, as has been demonstrated in this laboratory (17) and recently confirmed (18), the inaccuracies of oxygen determinations resulting from incomplete hemolysis of red cells by saponin in neutral solution do not occur (19). Duplicate determinations agreed within 0.05 vol. per cent for the most part and 0.10 vol. per cent in all cases.

PAH was determined as "total" PAH by acid hydrolysis of the conjugated material according to a modification of the method of Smith and his associates (20) in 11 cases and by the method of Newman and his associates (21) in the last four.

Mannitol was determined by a modification of Smith's method (22); endogenous creatinine was determined by the method outlined by Brod and Sirota (23); oxyhemoglobin determinations were done on the Evelyn photoelectric colorimeter (24) and hematocrits were determined according to the method of Wintrobe (25) with no correction for trapped plasma.

\section{Statistical methods}

To evaluate results, the standard error of measurement, $\sigma \mathrm{m}$, for each specific function has been calculated from the variability of multiple control determinations in each individual according to the formula $\sigma \mathrm{m}=\sqrt{\frac{\epsilon \mathrm{d}^{2}}{\mathrm{n}^{\prime}}}$, where $\mathrm{d}$ represents the deviation of each observation from the mean value for that subject and $n^{\prime}$ represents degrees of freedom calculated as the total number of observations minus the total number of subjects. The standard error of measurement of the mean of multiple determinations in a single subject equals $\frac{\sigma \mathrm{m}}{\sqrt{\mathrm{n}}}$ where $\mathrm{n}$ is the number of observations making up the mean. In the case of $Q_{0_{2}}$, the product of $(A-R)_{0_{2}}$ and $R B F$, the standard error of measurement has 
been calculated from the formula:

$$
\left(\frac{\sigma \mathrm{mT} Q_{0_{2}}}{\overline{\mathrm{TQ}_{\mathrm{O}_{2}}}}\right)^{2}=\left(\frac{\sigma \mathrm{m}(\mathrm{A}-\mathrm{R})_{0_{2}}}{\overline{(\mathrm{A}-\mathrm{R})_{02}}}\right)^{2}+\left(\frac{\sigma \mathrm{mRBF}}{\overline{\mathrm{RBF}}}\right)^{2}
$$

where $\overline{Q_{02}}, \overline{(A-R)_{02}}$ and $\overline{R B F}$ refer to the respective means. Dividing by three expresses $\sigma \mathrm{mQ}_{\mathrm{O}_{2}}$ in cc./100 grams/min.

Standard errors of measurement thus calculated for the various specific renal functions are shown in Table $I$. The standard error of measurement of the difference, $\sigma \mathrm{md}$, of each experimental value from its own control value was calculated according to the formula $\sigma \mathrm{md}$ equals $\sqrt{\sigma \mathrm{m}^{2} \mathrm{c}+\sigma \mathrm{m}^{2} \mathrm{e}}$ where $\sigma \mathrm{mc}$ and $\sigma \mathrm{me}$ are the standard errors of measurement of the control and experimental values respectively. Each difference was then divided by its standard error of measurement and the resulting " $t$ " value evaluated for significance at the 5 per cent level.

The significance of the means of the differences between control and experimental observations for all subjects taken together within each of the three test groups was evaluated by the usual " $t$ " test.

\section{RESULTS $^{5}$}

The data are given in Table II. None of the test procedures used resulted in consistent measurable changes in either $(A-R)_{O_{2}}$ or $Q_{O_{2}}$ and in only a single instance, $\mathrm{QO}_{2}$ in patient 6 , was the change significantly greater than might be expected on the basis of the error of the method. If one disregards patients 1,4 , and 6 there was no change in $(A-R)_{O_{2}}$ greater than 0.4 vol. per cent or in $\mathrm{Q}_{2}$ greater than $1.4 \mathrm{cc} . / 100$ grams/ min. Thus on a statistical basis no $t$ value would have been greater than 0.7. Likewise the mean differences are not statistically significant. Glomerular filtration rate as estimated by

TABLE I

Statistical basis for evaluation

\begin{tabular}{|c|c|c|c|}
\hline \multirow{2}{*}{ Specific renal function } & \multicolumn{3}{|c|}{$\begin{array}{l}\text { Standard error of measure- } \\
\text { ment when } n \text { equals }\end{array}$} \\
\hline & 1 & 2 & 3 \\
\hline $\begin{array}{l}\text { GFR cc./min. } \\
\text { Mannitol clearance } \\
\text { Creatinine clearance } \\
\text { RBF cc./min. } \\
(A-R)_{0} \text { vols. per cent } \\
Q_{0_{2}} \text { cc./100 grams/min. } \\
\text { Single }(A-R)_{0_{2}} \times \text { mean of } n \\
\text { RBF } \\
\text { Mean of } 2(A-R)_{0_{2}} \times \text { mean } \\
\text { of } n \text { RBF }\end{array}$ & $\begin{array}{r}8.4 \\
7.5 \\
168 \\
.37 \\
1.90 \\
1.45\end{array}$ & $\begin{array}{r}6.0 \\
5.3 \\
118 \\
.26 \\
1.82 \\
\\
1.34\end{array}$ & $\begin{array}{r}4.9 \\
4.3 \\
97 \\
.21 \\
1.79 \\
1.30\end{array}$ \\
\hline
\end{tabular}

Following the presentation of these data in abstract form, Bucht, Werkö, and Josephson have reported similar results associated with tubular saturation with PAH (26). endogenous creatinine increased significantly with water diuresis. At the onset of water diuresis, usually, for a single urine collection period, some of the subjects showed a transient increase in RBF (persistent in patient 8) which may have been due to hyperemia but may also possibly have been due to washout of $\mathrm{PAH}$ contained in the urinary dead space as the rate of diuresis increased. Such periods were not included in experimental averages and $(A-R)_{O_{2}}$ measurements were not made at times when it was anticipated that this change would occur, so as to avoid any possible effect on $\mathrm{Q}_{2}$ of hemodynamic changes per se, real or apparent, in contradistinction to effect on $\mathrm{QO}_{2}$ of changes in renal tubular functional activity.

The mean renal arterio-venous differences of the 15 subjects calculated from control observations only was 1.43 vols. per cent with a standard deviation of 0.39 and a standard error of the mean of 0.10 . The mean renal oxygen consumption was $6.24 \mathrm{cc} . / 100 \mathrm{grams} / \mathrm{min}$. with a standard deviation of 2.07 and standard error of the mean of 0.54 . These values are in good agreement with those of other workers for the metabolism of the normal kidney $(14,15,27)$.

\section{DISCUSSION}

These data indicate that, if changes in renal oxygen consumption occurred under the conditions of these experiments, such changes were masked by the error of measurement. While these measurements will detect only relatively large changes, they would be quite adequate to detect such changes as may occur in the body as a whole during exercise where oxygen consumption may increase 16 fold (28). Failure to obtain such a response means either that the stimuli were inadequate or that the kidney uses most of its oxygen for something other than the changes in work load we induced. Since the kidney is never entirely at rest, it may well be that the differences between control and experimental conditions were really quite small with respect to the total energy required in the complex process of converting glomerular filtrate into urine and maintaining the functional state of the renal cells. A relationship between urinary function and renal oxygen consumption is suggested by the data of Cargill and Hickam 
TABLE II

Effect on renal oxygen consumption of some changes in functional activity

\begin{tabular}{|c|c|c|c|c|c|c|c|c|c|c|c|c|c|c|c|c|}
\hline \multirow[t]{2}{*}{ Patient } & \multicolumn{2}{|c|}{$\begin{array}{c}\text { Tubular* } \\
\text { excretion } \\
\text { PAH } \\
\text { mg./min. }\end{array}$} & \multicolumn{2}{|c|}{$\begin{array}{l}\text { Rate of } \\
\text { diuresis } \\
\text { cc./min. }\end{array}$} & \multicolumn{2}{|c|}{$\begin{array}{c}\text { Urine } \\
\text { specific } \\
\text { gravity }\end{array}$} & \multicolumn{2}{|c|}{$\begin{array}{l}\text { U/P ratio } \\
\text { creatinine }\end{array}$} & \multicolumn{2}{|c|}{$\begin{array}{c}\text { Filtration } \\
\text { rate (GFR) } \\
\text { cc./min. }\end{array}$} & \multicolumn{2}{|c|}{$\begin{array}{l}\text { Renal blood } \\
\text { flow (RBF) } \\
\text { cc./min. }\end{array}$} & \multicolumn{2}{|c|}{$\begin{array}{l}\text { Renal A-V } \\
\text { O2 difference } \\
{\left[(A-R) O_{2}\right] \ddagger} \\
\text { ools. per cent }\end{array}$} & \multicolumn{2}{|c|}{$\begin{array}{c}\text { Renal } \mathrm{O}_{2} \\
\text { consumption } \\
\left(\mathrm{QO}_{2}\right) \\
\text { cc./100 } \mathrm{grams} / \mathrm{min}\end{array}$} \\
\hline & $C \&$ & E\& & c & $\mathbf{E}$ & c & $\mathbf{E}$ & c & $\mathbf{E}$ & C & $\mathbf{E}$ & $\mathrm{C}$ & $\mathbf{E}$ & C & $\mathbf{E}$ & C & $\mathbf{E}$ \\
\hline
\end{tabular}

I. PAH saturation

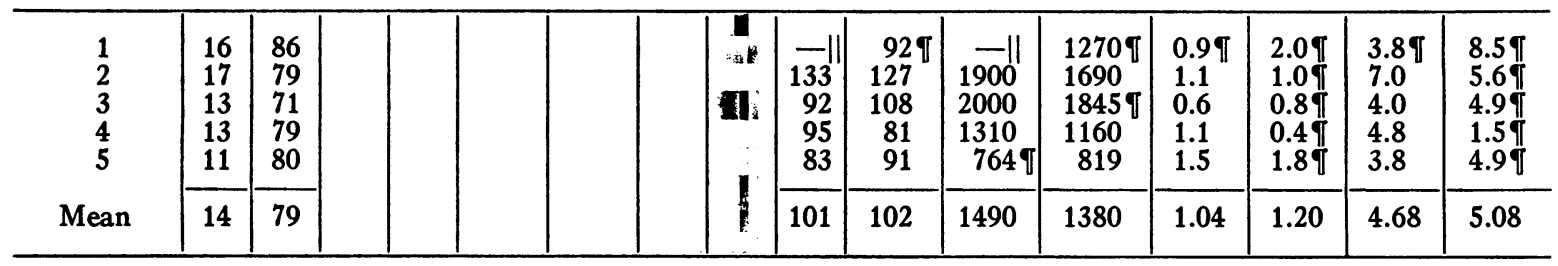

II. Water diuresis

\begin{tabular}{|c|c|c|c|c|c|c|c|c|c|c|c|c|c|c|}
\hline $\begin{array}{r}6 \\
7 \\
8 \\
9 \\
10\end{array}$ & $\begin{array}{l}0.5 \\
0.8 \\
0.5 \\
0.8 \\
0.8\end{array}$ & \begin{tabular}{r|}
7.5 \\
6.6 \\
12.5 \\
8.0 \\
3.1
\end{tabular} & $\begin{array}{l}1.022 \\
1.018 \\
1.022\end{array}$ & $\begin{array}{l}1.003 \\
1.001 \\
1.009\end{array}$ & \begin{tabular}{|r|}
163 \\
135 \\
232 \\
119 \\
83
\end{tabular} & $\begin{array}{r}9 \\
17 \\
11 \\
12 \\
22\end{array}$ & $\begin{array}{r}65 \\
99 \\
116 \\
95 \\
66\end{array}$ & $\begin{array}{c}70 \\
115^{* *} \\
137^{* *} \\
98 \\
69\end{array}$ & $\begin{array}{r}1840 \\
1350 \\
1540 \\
878 \\
855\end{array}$ & $\begin{array}{c}1690 \\
1560 \\
1830^{* *} \\
884 \\
923\end{array}$ & $\begin{array}{l}1.6 \\
2.19 \\
1.6 \\
1.6 \\
1.7\end{array}$ & $\begin{array}{l}0.8 \rrbracket \\
1.8 \rrbracket \\
1.3 \rrbracket \\
2.0 \\
1.5 \rrbracket\end{array}$ & $\begin{array}{l}9.8 \\
9.5 \pi \\
8.2 \\
4.7 \\
4.8\end{array}$ & $\begin{array}{l}4.5 \pi^{* *} \\
9.4 \pi \\
7.9 \pi \\
5.9 \\
4.6 \pi\end{array}$ \\
\hline Mean & 0.7 & 7.5 & & & 146 & 14 & 88 & $98^{* *}$ & 1093 & 1177 & 1.72 & 1.48 & 7.40 & 6.46 \\
\hline
\end{tabular}

III. Mannitol diuresis

\begin{tabular}{|c|c|c|c|c|c|c|c|c|c|c|c|c|}
\hline $\begin{array}{l}11 \\
12 \\
13 \\
14 \\
15\end{array}$ & $\begin{array}{l}0.9 \\
0.5 \\
0.4 \\
0.7 \\
0.6\end{array}$ & $\begin{array}{l}3.1 \\
4.4 \\
6.3 \\
7.8 \\
4.6\end{array}$ & $\begin{array}{l}121 \\
156 \\
215 \\
237 \\
170\end{array}$ & $\begin{array}{l}29 \\
18 \\
13 \\
22 \\
22\end{array}$ & $\begin{array}{r}109 \\
78 \\
86 \\
166 \\
102\end{array}$ & $\begin{array}{r}108 \\
79 \\
85 \\
172 \\
101\end{array}$ & $\begin{array}{r}1400 \\
1060 \\
984 \\
2210 \\
935\end{array}$ & $\begin{array}{c}1430 \\
1110 \\
1120 \\
2550^{* *} \\
915\end{array}$ & $\begin{array}{l}1.8 \rrbracket \\
1.6 \\
1.8 \\
1.2 \\
1.4\end{array}$ & $\begin{array}{l}1.69 \\
1.6 \\
1.9 \\
1.1 \\
1.6\end{array}$ & $\begin{array}{l}8.4 \rrbracket \\
5.7 \\
5.9 \\
8.8 \\
4.4\end{array}$ & $\begin{array}{l}7.6 \text { I } \\
5.9 \\
7.1 \\
9.4 \\
4.9\end{array}$ \\
\hline $\begin{array}{c}\text { Mean } \\
\text { Grand mean }\end{array}$ & 0.6 & 5.2 & 180 & 21 & 108 & 109 & 1318 & $\begin{array}{c}1425 \\
\text { mean } \\
\sigma \\
\sigma \overline{\mathrm{x}}\end{array}$ & $\begin{array}{l}1.56 \\
1.43 \\
0.39 \\
0.10\end{array}$ & 1.56 & $\begin{array}{l}6.64 \\
\\
6.24 \\
2.07 \\
0.54\end{array}$ & 6.98 \\
\hline
\end{tabular}

* Calculated by $\mathrm{Tm}_{\mathrm{PAH}}$ formula $\mathrm{T}=\mathrm{UV}-0.83 \mathrm{GFR} \times \mathrm{P}_{\mathrm{PAH}}$, where $\mathrm{T}=$ tubular excretion of PAH, UV $=$ urinary excretion of PAH, GFR = glomerular filtration rate, $\mathrm{P}_{\mathrm{PAB}}=$ plasma concentration of PAH.

$\uparrow$ Mannitol clearance in I, endogenous creatinine clearance in II and III.

$\$$ Corrected to equal hemoglobin concentrations.

$\$ \mathrm{C}=$ control, $\mathrm{E}=$ experimental determination.

II Values not obtained due to technical difficulties, experimental value of $R B F$ used to calculate $Q_{0_{2}}$ since variability of $(A-R)_{\mathrm{O}_{2}}$ is much greater than that of RBF.

T Single determination, all others average of 2 or 3.

** Statistically significant change from control value.

(15) who found a significant correlation between glomerular filtration rate and renal oxygen consumption. Their studies, however, included observations on patients with renal disease where, as the authors point out, metabolic properties may be altered. Hayman and Schmidt in 1928 (5) and Van Slyke and his associates in 1934 (8), on the basis of data in animals similar to these in humans, postulated that the bulk of energy resulting from renal oxygen consumption is expended for something other than external work.
Rapoport and his colleagues have determined that calculated renal osmotic work can be increased by solute loading up to a maximum value of about 4.0 calories/min./1.73 square meters (3). On this basis, since $1 \mathrm{cc}$. of oxygen is approximately equivalent to 5 calories (only minor errors would be introduced by varying R. Q.), a change from resting state to one of maximal osmotic work should cause an increase in $Q_{O_{2}}$ of roughly $0.3 \mathrm{cc} . / 100$ grams $/ \mathrm{min}$., or only 5 per cent of our mean value for oxygen con- 
sumption of the human kidney. As these authors have pointed out (29), one may question the physiologic significance of such thermodynamic calculations since they consider only the overall osmolar gradient between plasma and bladder urine, and processes such as glucose reabsorption, which might require considerable energy expenditure, are not represented as net work, since they are balanced by water reabsorption with no osmolar change in tubular urine.

Nevertheless, the fact that in vitro determinations of renal oxygen consumption where no urine is being formed $(30,31)$, when recalculated into the same units as our data, give results of comparable magnitude also supports the concept that most of the oxygen used by the kidney is not used for external work.

Thus the metabolic state of the kidney might be regarded as one of dynamic equilibrium in an open-ended system as recently discussed by von Bertalanffy (32). In such a system the bulk of energy is expended to maintain the steady state which enables work to be done, and external functional processes, such as urine formation, could be accomplished with little added energy beyond the basic needs of the organ.

Applied to the clinical level, if it be true that the great bulk of renal metabolism goes on more or less independently of osmotic work being done, such a concept might suggest that whatever may be the value of special diets in the treatment of renal disease, such value is not dependent on "resting the kidney" by decreasing solute load.

\section{SUMMARY}

1. By means of clearance techniques with renal vein catheterization renal oxygen consumption has been measured in unanesthetized man before and during (a) saturation of the tubular transport mechanism for $\mathrm{PAH},(b)$ water diuresis, and $(c)$ osmotic diuresis induced by mannitol.

2. The mean renal oxygen consumption in $\mathbf{1 5}$ subjects was $6.24 \mathrm{cc} . / 100 \mathrm{grams} / \mathrm{min}$. with a standard deviation of 2.07 and a standard error of the mean of 0.54 .

3. The mean renal arterio-venous oxygen difference was 1.43 vols. per cent with a standard deviation of 0.39 and a standard error of the mean of 0.10 .
4. These values are in reasonably close agreement with in vitro work.

5. There was no statistically significant change in renal oxygen consumption between the control and test measurements.

6. These data suggest that the bulk of oxygen consumed by the kidney is used for purposes not measurable by external work.

7. The data suggest that any beneficial results of special diets in renal disease do not result from resting the kidney by decreasing the oxygen requirement as a result of diminution of external work.

\section{REFERENCES}

1. Bodansky, M., Introduction to Physiological Chemistry. John Wiley \& Sons, Inc., New York, 1934, Ed. 3, p. 525.

2. Barcroft, J., and Brodie, T. G., The gaseous metabolism of the kidney. J. Physiol., 1905, 33, 52.

3. Rapoport, S., Brodsky, W. A., West, C. D., and Mackler, B. Urinary flow, excretion of solutes, and osmotic work during diuresis of solute loading in hydropenia in man. Science, 1948, 108, 630.

4. Barcroft, J., and Brodie, T. G., The gaseous metabolism of the kidney. J. Physiol., 1905, 32, 18.

5. Hayman, J. M., Jr., and Schmidt, C. F., The gaseous metabolism of the dog's kidney. Am. J. Physiol., 1928, 83, 502.

6. Kramer, K., and Winton, F. R., The influence of urea and of change in arterial pressure on the oxygen consumption of the isolated kidney of the dog. J. Physiol., 1939, 96, 87.

7. Fee, A. R., A note on the effect of sodium sulfate on the oxygen usage of the kidney. J. Physiol., 1929, 67, 14.

8. Van Slyke, D. D., Rhoads, C. P., Hiller, A., and Alving, A. S., Relationships between urea excretion, renal blood flow, renal oxygen consumption, and diuresis. The mechanism of urea excretion. Am. J. Physiol., 1934, 109, 336.

9. Goldring, W., and Chasis, H., Hypertension and Hypertensive Disease. The Commonwealth Fund, New York, 1945, Ed. 3.

10. Earle, D. P., and Berliner, R. W., A simplified clinical procedure for measurement of glomerular filtration rate and renal plasma flow. Proc. Soc. Exper. Biol. \& Med., 1946, 62, 262.

11. Baldwin, D. S., Schreiner, G. E., Breed, E. S., Wesson, L. G., Jr., and Maxwell, M. H., Depression of apparent p-aminohippurate extraction ratio by glucose. J. Clin. Invest., 1950, 29, 614.

12. Reubi, F. C., and Schroeder, H. A., Can vascular shunting be induced in the kidney by vasoactive drugs? J. Clin. Invest., 1949, 28, 114.

13. Dole, V. P., Emerson, K., Jr., Phillips, R. A., Hamilton, P., and Van Slyke, D. D., The renal extraction 
of oxygen in experimental shock. Am. J. Physiol., 1946, 145, 337.

14. Bradley, S. E., and Halperin, M. H., Renal oxygen consumption in man during abdominal compression. J. Clin. Invest., 1948, 27, 635.

15. Cargill, W. H., and Hickam, J. B., The oxygen consumption of the normal and diseased human kidney. J. Clin. Invest., 1949, 28, 526.

16. Van Slyke, D. D., and Neill, J. M., The determination of gases in blood and other solutions by vacuum extraction and manometric measurement. J. Biol. Chem., 1924, 61, 523.

17. Cummins, A. J., Clark, J. K., Crosley, A. P., Jr., and Barker, H. G., Effect of various types of hemolytic agents in the combined determination of oxygen and carbon dioxide in blood. J. Lab. \& Clin. Med., 1950, 35, 164.

18. King, R. M., The effectiveness of lactic acid as a hemolytic agent in the determination of blood oxygen. J. Biol. Chem., 1950, 184, 485.

19. Hiller, A., Plazin, J., and Van Slyke, D. D., Substitutes for saponin in the determination of oxygen and carbon monoxide of blood. J. Biol. Chem., 1948, 176, 1431.

20. Smith, H. W., Finkelstein, N., Aliminoșa, L., Crawford, B., and Graber, M., The renal clearances of substituted hippuric acid derivatives and other aromatic acids in dog and man. J. Clin. Invest., $1945,24,388$.

21. Newman, E., Kattus, A., Genecin, A., Genest, J., Calkins, E., and Murphy, J., Observations on the clearance method of determining renal plasma flow with diodrast, para-aminohippuric acid (PAH) and para-acetyl-aminohippuric acid (PACA). Bull. Johns Hopkins Hosp , 1949, 84, 135.

22. Barker, H. G., and Clark, J. K., Effect of paraaminohippurate on mannitol determinations by the periodate-iodide-thiosulfate method. Proc. Soc. Exper. Biol. \& Med., 1947, 64, 120.

23. Brod, J., and Sirota, J. H., The renal clearance of endogenous "creatinine" in man. J. Clin. Invest., 1948, 27, 645.

24. Evelyn, K. A., A stabilized photoelectric colorimeter with light filters. J. Biol. Chem., 1936, 115, 63.

25. Wintrobe, M. M., A simple and accurate hematocrit. J. Lab. \& Clin. Med., 1929, 15, 287.

26. Bucht, H., Werkö, L., and Josephson, B., The oxygen consumption of the human kidney during heavy tubular excretory work. Scandinav. J. Clin. \& Lab. Invest., 1949, 1, 277.

27. Mokotoff, R., Escher, D. J. W., Edelman, I. S., Grossman, J., Leiter, L., Weston, R. E., Zweifach, B. W., and Shorr, E., Vasotropic principles in blood (VEM and VIM) and renal hemodynamics in chronic heart failure. Federation Proc., 1949, 8, 423.

28. Wright, S., Applied Physiology. Oxford University Press, New York, 1936, Ed. 6, p. 505.

29. Rapoport, S., West, C. D., and Brodsky, W. A., Excretion of solutes and osmotic work during osmotic diuresis of hydropenic man. The ideal and the proximal and distal tubular work; the biological maximum of work. Am. J. Physiol., $1949,157,363$.

30. Crismon, J. M., and Field, J., Jr., The oxygen consumption in vitro brain cortex, kidney, and skeletal muscle from adrenalectomized rats. Am. J. Physiol., 1940, 130, 231.

31. Eisenbrandt, L. L., and Elliott, H. W., Comparative in vivo and in vitro effects of methadone upon the $\mathrm{QO}_{2}$ of rat liver, kidney, and jejunum. J. Pharmacol. \& Exper. Therap., 1949, 97, 120.

32. von Bertalanffy, L., The theory of open systems in physics and biology. Science, 1950, 111, 23.

\section{SPECIAL NOTICE}

A foreign medical library is in need of the January, 1944, Vol. 23, No. 1 issue of the J.C.I. to complete their series. If this missing number, which is out of stock, may be obtained, please contact :

Journal of Clinical Investigation

Business Office

c/o Cincinnati General Hospital

Cincinnati 29, Ohio 